\title{
When taking medication may be a sin: dietary requirements and food laws in psychotropic prescribing
}

\author{
Waqqas A. Khokhar, Simon L. Dein, Mohammed S. Qureshi, Imran Hameed, \\ Mohammed M. Ali, Yasir Abbasi, Hasan Aman \& Ruchit Sood
}

\begin{abstract}
SUMMARY
Religious laws do not usually forbid the use of psychotropic medication, but many do forbid the consumption of animal-based derivatives of bovine and/or porcine origin (e.g. gelatin and stearic acid) such as are found in many medications. Demonstrating awareness of this, combined with a genuine concern about how it affects the patient, may strengthen the doctor-patient relationship and avoid non-adherence. In this article, we outline dietary requirements of key religions and belief systems that may have a bearing when prescribing medication containing animal-based ingredients. We identify common psychotropics that contain animal-based derivatives and suggest alternative prescribing options and approaches to dealing with sensitive ethical issues.
\end{abstract}

\section{LEARNING OBJECTIVES}

- Gain a basic understanding of religious principles governing dietary laws and their influence on concordance with psychotropic medication

- Be able to discuss confidently with patients the presence of religiously or ethically forbidden ingredients in medication

- Be able to offer alternative strategies to address medication non-adherence secondary to religious, ethical or personal beliefs

\section{DECLARATION OF INTEREST}

None

Medication is probably the most frequently prescribed treatment in mental healthcare and non-adherence has a significant impact on patients' lives and well-being (Weiden 1995; Patel 2005). Although religious beliefs may not markedly influence medication adherence in patients who present to psychiatric services (Dein 2004), non-adherence should prompt a comprehensive assessment of the patient's demographics, social circumstances, and cultural and religious beliefs (Subach 1999; Sattar 2004a).
In psychiatric practice, it is not uncommon to come across patients who refuse any psychiatric intervention, placing their faith in a spiritual recovery enabled by their religious beliefs (Campion 1997; Koenig 2001). Although religious laws do not usually restrict the taking of psychotropic medication, many do forbid consumption of the animal derivatives, particularly gelatin and stearic acid, that many psychotropics contain. This has major implications, for example, for patients who follow Judaism, Islam, Hinduism, Buddhism and Seventh Day Adventism (Singsit 2001; Leung 2005). There are also over 4 million vegetarians in the UK and the number is ever growing (Food Standards Agency 2005).

The experience of illness can be akin to a spiritual event for many psychiatric patients. Patients, carers and their families may be more likely to consult religious teachings during times of illness (Borras 2007; Chatters 2008). A discussion about the presence of animal products in medications not only opens the door to a dialogue with people for whom the psychiatrist pledges to care but also shows a willingness to acknowledge that their beliefs are important to the psychiatrist (Huguelet 2006). Lack of consideration for these matters can impair the doctor-patient relationship (Khokhar 2008). Although there has been little research in this area (e.g. Mohr 2004; Sattar 2004b; Dogra 2005), the fostering of patients' trust through a shared understanding of their illness can improve treatment adherence, reduce relapse rates and thus help to reduce their mental distress (Borras 2007). There is also evidence to suggest that the patients of clinicians who respect their perspectives have improved healthcare outcomes and feel better understood, respected and valued as partners in their own care (Secker 2002). Williams (1997) argued that, when culture is overlooked, incorrect and even harmful decisions may be made. Good patient care is not only culturally aware, but also religiously sensitive. Such care requires

ARTICLE

Waqqas A. Khokhar is a consultant psychiatrist with Leicestershire Partnership NHS Trust and an honorary lecturer in the Centre for Ageing and Mental Health at Staffordshire University. Simon L. Dein is a senior lecturer at University College London, an Honorary Clinical Professor at the University of Durham and a consultant psychiatrist with the North Essex Partnership University NHS Foundation Trust. Mohammed S. Oureshi is a Foundation Year One Doctor at United Lincolnshire Hospitals, having recently gained an MB ChB degree from Leicester Medical School. Imran Hameed is a GP registrar with the East of England GP Rotational Training Scheme. He is based in Peterborough. Mohammed M. Ali is a consultant forensic psychiatrist with St Andrew's Healthcare Service, Northampton. Yasir Abbasi is a consultant addiction psychiatrist with the Leeds Addiction Unit, Leeds \& York Partnership NHS Foundation Trust and an honorary senior lecturer in the School of Healthcare, University of Leeds. Hasan Aman works with Northumberland, Tyne and Wear NHS Foundation Trust as a consultant child and adolescent psychiatrist in Newcastle upon Tyne. Ruchit Sood is a consultant in general psychiatry with the Betsi Cadwaladr University Health Board, Wrexham, Wales. Correspondence Dr Waqqas Ahmad Khokhar, Department of Psychiatry, Maidstone Centre, City Central CMHT, St Peters Health Centre, Sparkenhoe Street, Leicester LE2 OTA, UK. Email: waqqaskhokhar@doctors.org.uk 
commitment, willingness to honour differences and openness to exploring diversity. It also requires mental health professionals to be more aware of issues of religion and spirituality and educated about the major teachings of diverse religious groups (Meyer 1988).

\section{Dietary requirements and food laws from a religious perspective}

\section{The concept of clean and unclean animals}

Followers of many religions forbid the consumption of certain animals, which are commonly referred to as 'unclean'. Some religions also have specific requirements with regard to the slaughtering of animals and the preparation of meat and meat products. These issues are prominent in Judaism and Islam, where pork is not consumed, and they are largely used as the basis for identifying 'taboo' meat proscribed by religious dietary laws. For certain faiths, medicines derived from sources that are forbidden can present huge problems for patients, carers as well as healthcare professionals. Methods for determining what is and is not acceptable among people of particular religious creeds remain a source of discussion by religious leaders and scholars (Eriksson 2013).

\section{The Abrahamic faiths}

A brief word on the concept of Abrahamic faiths and their common ground will aid the understanding of references to non-Abrahamic faiths later in this article. Judaism, Christianity and Islam are the three religions collectively referred to as the Abrahamic faiths. All are monotheistic religions and are unified in their belief that God revealed himself to the Prophet Abraham. Thus, the Prophet Abraham is the common forefather of these faiths, which currently embrace more than half of the world's population. According to this trio of religions, God is the Divine Creator and source of all moral law. All other faiths, including the dharmic religions and the Chinese religions of East Asia, are therefore termed non-Abrahamic faiths. The non-Abrahamic faiths that we discuss in this article are Hinduism, Buddhism and Sikhism.

\section{Judaism \\ Views on animals}

God created animals and His covenant with the animals was to promise that they would be properly looked after. God created humans and gave them dominion over the animals. Humans are given detailed rules and regulations on how to take care of animals. Several passages in Jewish scriptures exhibit concern for the psychological and physical well-being of animals. For example, Exodus 23:5 and Deuteronomy 22:4 both talk about relieving animals of their burden, regardless of whether their owner is a friend or an enemy.

\section{Jewish dietary laws}

Kashrut comes from the Hebrew root Kaf-ShinReish, meaning fit, proper or correct. According to Jewish dietary laws (Kashrut), only animals that chew the cud (ruminate) and have cloven hooves, for example cows, can be consumed. Pigs are forbidden, as they do not chew the cud despite having cloven hooves. Horses and camels do chew the cud, but do not have cloven hooves. Thus, Jews are forbidden to eat pork, as swine are considered to be unclean (Dresner 1980).

Meat must be kosher, which is achieved by the ritual slaughter of the animal (schechita) with respect and compassion by a religious Jew who is trained and licensed. Kosher dietary laws are observed all year round, not just during Pesach (Passover). Any products of a non-kosher animal are also non-kosher (Heber 1995). Gelatin is one such product, and within the past 20 years, kosher gelatin has become available: some of this is derived from cows or fish and some is derived from a plant or seaweed base using agar or pectin.

\section{What does this mean for the Jewish patient?}

According to Jewish teachings, people who are ill fall into one of three categories:

- choleh sheyesh bo sakanah: someone who is ill and whose life may be in danger as a result of the illness;

- choleh she'ain bo sakanah: someone who is ill but whose life is not likely to be in danger; this includes those who are bedridden and those who are not functioning at normal levels owing to pain or illness;

- one who has a michush: someone who is uncomfortable but is able to maintain routine activities despite discomfort, for example those with a headache or indigestion.

Jewish medical ethics derived from Jewish law (halacha) provide guidance on the use of medicinal substances. All food and dietary additives or medicines that are swallowed must contain only kosher ingredients. However, porcine or other non-kosher material administered in a non-edible manner is permitted in the case of choleh sheyesh bo sakanah and choleh she'ain bo sakanah. Therefore, there are no restrictions or prohibitions on the injection or administration by other parenteral methods of non-kosher products such as porcine insulin. However, a rabbi must be 
consulted in matters pertaining to consumption of non-kosher medication by someone who has a michush (Adler 2007).

Islam

Views on animals

Islam, like the other Abrahamic faiths, sees animals in a very positive light. It considers them as signs and worshippers of God, hence worthy of great respect. The Qur'an refers to animals as communities in their own right, stating: 'And there is no creature on the earth or bird that flies with wings except [that they are] communities like you' (Qur'an 6:38). Rules of interaction with animals are addressed in the Hadith (the collective body of traditions relating to Muhammad and his companions), in which Muhammad compares acts of cruelty to animals with cruel acts to humans.

\section{Islamic dietary laws}

According to Islamic dietary laws, several animals are considered unclean and not to be eaten (haraam), while others are permitted (halaal) as long as they have been killed or slaughtered in the correct manner (dabiaah). The Qu'ran states this clearly: 'Forbidden to you are: dead meat, blood, the flesh of swine, and that on which hath been invoked the name of other than Allah; that which hath been killed by strangling, or by a violent blow, or by a headlong fall, or by being gored to death; that which hath been eaten by a wild animal; unless ye are able to slaughter it; that which is sacrificed on stone [Altar?]; [forbidden] also is the division by raffling with arrows: that is impiety' (Qur'an 5:3).

According to Islamic law (sharee'ah), the most important condition of dabiaah is that basmala or tasmiyah (reciting the name of Allah) be performed at the time of slaughter. Several verses of the Qu'ran explain that meat of those animals whose slaughter was not performed in this manner is forbidden. The meat of animals slaughtered by a kafir (non-believer) or mushrik (polytheist) is also forbidden. This means that, although Muslims are permitted to eat bovine meat, if it has not been slaughtered according to the Islamic laws, then it cannot be consumed (Usmani 2006).

The products of a non-halaal animal are also considered non-halaal. However, in the case of gelatin, there is a considerable variation in views. One less accepted belief is that, owing to change in its chemical nature (istihalah) during the process of its derivation from animal hides and bones, gelatin derived from non-halaal animals becomes halaal (Hashim 2009).
What does this mean for the Muslim patient?

If the prescription is 'life saving' then all treatments are permissible. If 'preventive' or 'life enhancing', then there is some room for doubt and a number of Muslims either use their own discretion or consult an Imam (a religious leader). As a broad guide: if a medication contains alcohol or pig products, then it must not be taken orally but parenteral or external application is probably permitted. The use of porcine-derived material for life-threatening illness may become temporarily exempt from the dietary laws, but the decision requires discussion with religious leaders or Imams (Gatrad 2001).

\section{Comparison of Judaism and Islam}

Table 1 outlines the main differences between Jewish and Islamic dietary laws. In reviewing these, healthcare professionals should recognise that within each faith there are many schools of thought. In addition, different cultures will have different customs that will be intertwined with religious law. The extent to which people adhere to each religious teaching is a matter for the individual. The intensity of religious practice may vary according to an individual's situation: for example, as mentioned earlier, patients, carers and families may place greater importance on religious needs at times of ill health. Adherence to religious dietary laws in relation to medication is a wide-ranging issue and heterogeneous religious communities can vary in individual practices.

\section{TABLE 1 Dietary laws in Judaism and Islam: principle differences and similarities}

\begin{tabular}{|c|c|c|}
\hline & Judaism & Islam \\
\hline Basic rule & $\begin{array}{l}\text { Only foods that are explicitly } \\
\text { permitted, or kosher, can be eaten. } \\
\text { Forbidden foods are known as traif. }\end{array}$ & $\begin{array}{l}\text { Any food that is not explicitly } \\
\text { forbidden (haraam) is permitted } \\
\text { (halaal). }\end{array}$ \\
\hline Meat & $\begin{array}{l}\text { Only cloven-hoofed animals that } \\
\text { chew their cud can be eaten, e.g. } \\
\text { cows, sheep, goats and deer. Pigs are } \\
\text { forbidden. By-products of prohibited } \\
\text { animals are also prohibited. }\end{array}$ & $\begin{array}{l}\text { Only pigs and their by-products are } \\
\text { explicitly prohibited in the Qur'an. } \\
\text { Animals with claws and fangs are } \\
\text { prohibited implicitly but not explicitly. } \\
\text { Some foods are considered disliked } \\
\text { (makruh), but not prohibited }\end{array}$ \\
\hline Slaughter & $\begin{array}{l}\text { The animal's throat must be slit in a } \\
\text { quick and merciful manner. Any other } \\
\text { form of death renders the animal non- } \\
\text { kosher. After slaughter, the carcass } \\
\text { is examined for defects, the presence } \\
\text { of which makes the meat non-kosher. } \\
\text { Blood must be drained from the body, } \\
\text { and the meat washed and soaked } \\
\text { in salt. }\end{array}$ & $\begin{array}{l}\text { The animal's throat must be slit in a } \\
\text { quick and merciful manner. Drinking } \\
\text { of blood is prohibited, and this means } \\
\text { that all blood must be drained from } \\
\text { the body. The meat of any animal } \\
\text { killed by a blow, falling from a height, } \\
\text { or gored by horns is prohibited. }\end{array}$ \\
\hline Other & $\begin{array}{l}\text { Any food that has been consecrated } \\
\text { to an idol is prohibited. Eating meat } \\
\text { and dairy products in the same meal } \\
\text { is not permitted. }\end{array}$ & $\begin{array}{l}\text { Any food that has been consecrated } \\
\text { to another deity is prohibited (kosher } \\
\text { food is permitted, since it is killed in } \\
\text { the name of Allah's earlier revelation). }\end{array}$ \\
\hline
\end{tabular}




\section{Christianity}

Views on animals

The Christian view on animals has varied over the course of time. Christian thinkers in the past believed that humans were far superior to animals and that there were few, if any, moral obligations towards animals. However, modern Christians take a much more pro-animal line and believe that human dominion over nature should be seen as stewardship and partnership rather than domination and exploitation (Kemmerer 2011).

\section{Christian dietary laws}

In the very early days of Christianity it was debated whether converts ought to follow Jewish customs (including the dietary laws) or not. The commonly held theological position is that with the death and resurrection of Jesus, the 'old Covenant' and its restrictions no longer apply. The Epistle of Paul to the Colossians states: 'He forgave us all our sins, having cancelled the written code, with its regulations [...] Therefore do not let anyone judge you by what you eat or drink, or with regard to a religious festival, a New Moon celebration or a Sabbath day' (Colossians 2:13-14,16). Accordingly, Christians permitted themselves to eat pork, despite the fact that the Torah prohibits it. The main modern day exception to this is the denomination of Seventh Day Adventists, whose cofounder Ellen G. White was a proponent of vegetarianism. Adventists do not eat pork or other unclean meat as identified in the Book of Leviticus. Many Seventh Day Adventists avoid meat for health reasons, although vegetarianism is not a requirement.

\section{What does this mean for the Christian patient?}

The question of taking medication is most straightforward in Christianity. Christians, with the exception of Seventh Day Adventists, are generally permitted to consume all animals, including pork, as well as any drug excipients derived from animals.

\section{Ahimsa, non-Abrahamic faiths and vegetarianism}

Ahimsa

Ahimsa is a religious doctrine that advocates nonviolence and a respect for all life. It is interpreted most often as meaning peace and reverence towards all sentient beings. Ahimsa is the core of Hinduism, Jainism and Buddhism. Hinduism's vast scriptures widely prescribe vegetarianism based on profound links between ahimsa, karma (ill effects on oneself as a result of mistreatment of others) and reincarnation (the beginning of a new life for one's soul after biological death) to achieve a balance in one's 'spiritual ecology'. Most of the secular motivations for vegetarianism, such as ethical considerations and nutrition, apply to Hindu, Buddhist and Jain motivation as well (Walters 2001).

\section{Hinduism}

Hindu teachers and scriptures often expressly encourage a vegetarian diet in which meat, fish, poultry and eggs are forbidden, although dairy products are allowed. However, not all Hindus are vegetarians. Regardless of whether vegetarian or meat eaters, Hindus almost universally avoid beef since they consider the cow sacred.

\section{Buddhism}

Siddhartha Gautama, the Buddha, is widely believed to be a Hindu by birth and he accepted many of the Hindu core doctrines, such as karma. He explicitly taught vegetarianism as a component of his general instruction to be mindful and compassionate. It is not surprising that the term 'sentient being' is used repeatedly in Buddhist writings and refers to both humans and animals. Buddhists aim to relieve the sufferings of all sentient beings. Rebirth is a basic tenet of Buddhism and it includes rebirth of humans as other animals and vice versa. As a result, many Buddhists do not kill animals and many also do not eat meat (Phelps 2004). Many vegetarian Buddhists are not vegan, but for those who are, their choice often rests on objections to the conditions in which the animals producing products such as milk and eggs are raised. There are, however, no universally agreed rules for permitted and not-permitted foods in Buddhism (Kemmerer 2011).

\section{Sikhism}

Sikhism arose as a separate religion from Hinduism about 500 years ago, but it is still markedly influenced by Hinduism: it shares a culture and a world view involving ideas of karma, rebirth and an emphasis on individuals and families to maintain a lifestyle conducive to physical and mental health (Graham 2004). Sikhism, like many other world faiths, has a number of different sects. In the Akhand Kirtani Jatha sect, eating any meat is believed to be forbidden, yet this is not a universally held belief among Sikhs (Eriksson 2013). Sikhs can only eat the meat of an animal slaughtered by the jhatka method, whereby the animal is killed quickly, with one stroke of the weapon causing instantaneous death. Vegetarian 
TABLE 2

\begin{tabular}{|lll|}
\hline & Forbidden & Permitted \\
\hline $\begin{array}{l}\text { Lacto } \\
\text { vegetarianism }\end{array}$ & Meat, eggs & Dairy products \\
\hline $\begin{array}{l}\text { Ovo-lacto } \\
\text { vegetarianism }\end{array}$ & Meat & $\begin{array}{l}\text { Eggs, dairy } \\
\text { products }\end{array}$ \\
\hline $\begin{array}{l}\text { Ovo } \\
\text { vegetarianism }\end{array}$ & $\begin{array}{l}\text { Meat, dairy } \\
\text { products }\end{array}$ & Eggs \\
\hline $\begin{array}{l}\text { Dietary } \\
\text { veganism }\end{array}$ & $\begin{array}{l}\text { Meat, eggs, } \\
\text { dairy products }\end{array}$ & \\
\hline Veganism & $\begin{array}{l}\text { Meat, eggs, } \\
\text { dairy products, } \\
\text { animal leather }\end{array}$ & \\
\hline Fruitarianism & $\begin{array}{l}\text { Meat, eggs, } \\
\text { dairy products }\end{array}$ & Botanic fruits \\
\hline
\end{tabular}

sikhs are prohibited from consuming animalderived ingredients such as gelatin, certain thickeners (e.g. chitin) and animal-based lecithin emulsifiers.

\section{Vegetarians and vegans}

Vegetarianism is not a religion, but rather the practice of not eating meat, including beef, poultry, fish and their by-products (such as lard, tallow, gelatin, rennet and cochineal). The exclusion may also extend to dairy products and eggs. Vegans may be considered the strictest vegetarians, but vegetarianism encompasses a host of other subtypes (Table 2). Motivations behind various practices of vegetarianism are listed in Box 1.

\section{Use of animal-derived products in medication}

The inert substances derived from meat products that are frequently used in medications include gelatin, stearic acid, lactose, shellac, lanolin and beeswax. Of these, gelatin is the most commonly and widely used in pharmaceuticals, although stearic acid comes a close second. Concerns about the use of animal products in medications are not limited to those with particular religious beliefs (Singsit 2001; Leung 2005). Individuals with a stated preference to adhere to vegetarian or vegan diets might also prefer to avoid all such medications.

Gelatin is derived from collagen, a protein found in animal skin and bones. The most common sources of the collagen used in gelatin are pigs and cows. Gelatin is predominantly used in the manufacture of capsules. Hard-shell capsules are produced from gelatin solutions, whereas soft-shell capsules are made from gelatin films. A review of the Physicians' Desk Reference (www.pdr. net) reveals that 336 listed medications contain
BOX 1 Motivations behind various practices of vegetarianism

\begin{tabular}{ll}
\hline Religious & Individuals may choose to live a vegetarian life on the basis of their \\
& religious values, for example in Hinduism and Jainism. \\
Nutritional & Vegetarians argue that being vegetarian has numerous health benefits \\
& and prevents incidence of diseases such as ischaemic heart disease, \\
& hypertension and type 2 diabetes. \\
Ethical & Issues include the inhumane treatment of animals before slaughter, \\
& animal rights and that animals have the right to life particularly as there \\
& are alternative sources of nourishment and sustenance. \\
Environmental & Environmental vegetarianism revolves around the concern that eating \\
& meat is environmentally damaging and that production of meat and \\
animal products on a mass scale are environmentally unsustainable. & Animal agriculture is a cause of land degradation, loss of biodiversity, air \\
and water pollution as well as being a major contributor to greenhouse \\
gases and, thus, climate change. \\
The basis for economic vegetarianism is that the consumption of meat \\
is expensive and there are issues of public health and curbing world \\
starvation. \\
Spirituality does not necessarily coincide with being religious. A person \\
can be deeply spiritual without following a religious faith. Spiritual \\
vegetarians feel that eating meat harms them spiritually and damages \\
their soul.
\end{tabular}

gelatin as an inert substrate. Table 3 lists some of the most commonly prescribed psychotropics that contain gelatin.

\section{Clinical implications}

Prescribing medication containing animalderived gelatin and/or stearic acid is sometimes unavoidable. However, people who follow certain belief systems may well be committing a 'sin' if they take it. Thus, they face the dilemma of compromising their deeply held religious values or their health (Sattar 2004b). As practice shows, some choose the latter course. This has obvious implications not only for patients but also for physicians, who may find themselves facing ethical and even legal challenges. It is therefore imperative that clinicians discuss this matter with patients fully and frankly before any agreement is reached on the use of psychotropic medication. The patient information sheet shown in Fig. 1 might help in initiating such discussion.

Psychiatrists should be familiar with religious dietary restrictions (Meyer 1988) and should make every effort to identify patients with dietary restrictions arising from religious, cultural or personal beliefs (Royal College of Psychiatrists 2004). They should educate patients on the ingredients in their medication and be aware of alternative treatments consistent with patients' beliefs (Box 2). In many cases an offending medication can be safely avoided. 
Commonly prescribed brand name psychotropic medications that contain gelatin

\begin{tabular}{|c|c|}
\hline Brand name & Generic name \\
\hline \multicolumn{2}{|l|}{ Antipsychotics } \\
\hline Clopixol tablet & Zuclopenthixol decanoate \\
\hline Fluanxol/Depixol tablet & Flupentixol \\
\hline Risperdal Quicklet orodispersible tablet & Risperidone \\
\hline Zyprexa orodispersible tablet & Olanzapine \\
\hline Serenace capsule & Haloperidol \\
\hline Sulpitil tablet ${ }^{\mathrm{a}}$ & Sulpiride \\
\hline Stelazine tablet & Trifluoperazine \\
\hline Navane capsule ${ }^{a}$ & Thiothixene (tiotixene) \\
\hline Trilafon tablet & Perphenazine \\
\hline \multicolumn{2}{|l|}{ Antidepressants } \\
\hline Anafranil capsule ${ }^{a}$ & Clomipramine \\
\hline Cipramil tablet & Citalopram \\
\hline Cymbalta capsule & Duloxetine \\
\hline Edronax tablet & Reboxetine \\
\hline Efexor XL capsule & Venlafaxine slow release \\
\hline Molipaxin tablet & Trazodone \\
\hline Prothiaden capsule & Dosulepin \\
\hline Prozac capsule & Fluoxetine \\
\hline Surmontil capsule & Trimipramine \\
\hline Sinequan capsule ${ }^{a}$ & Doxepin \\
\hline \multicolumn{2}{|l|}{ Mood stabilisers } \\
\hline Eskalith capsule/controlled release tablet ${ }^{a}$ & Lithium carbonate \\
\hline Liskonum tablet & Lithium carbonate \\
\hline \multicolumn{2}{|l|}{ Anxiolytics } \\
\hline Librium capsule & Chlordiazepoxide \\
\hline
\end{tabular}

a. These preparations are not currently licensed in the UK.

Adapted from Sattar et al (2004b) and McAllister-Williams \& Ramplin (2009).

Information on the gelatin or stearic acid content of medications may not be readily available to prescribers and patients. However, it can be obtained directly from the manufacturers or from sources such as the Physicians' Desk Reference (www.pdr.net) and RxList (www.rxlist.com).

Some medications (modified-release, controlledrelease and gastroresistant preparations) already note the presence of gelatin in capsules, but the information is usually confined inconspicuously to the product information leaflet. A logical solution would be to clearly label medications with a single identifiable logo or mark (e.g. a crossed-out 'V', reflecting the ' $\mathrm{V}$ ' sign used on vegetarian-approved food products). Such product label guides have now become the accepted and expected norm for many foods.

It can sometimes be helpful to involve community leaders or religious scholars in the decisionmaking process, not only to aid understanding of these sensitive issues but also to instil a spirit

\section{Patient information}

Animal products in medication

Doctors in the UK are clearly instructed by the General Medical Council to do their best to find out anything about you, their patient, that might influence the decision they reach about your treatment. This includes food laws related to your religious or ethical beliefs.

Does this affect me?

Most faiths do not restrict the use of medication to treat mental illness. However, some of these medications contain animal-derived gelatin or stearic acid. Gelatin is made from the bones and hides of pigs or cattle and is often used to make capsules. Stearic acid is made from cow or pig fat and it can be present in tablets, gels, capsules, creams and lotions. Using animal products can have major personal and religious implications for vegetarian, Muslim, Jewish and Hindu communities, to name but a few.

\section{What can I do about it?}

If you are worried that your medication contains a religiously or personally forbidden ingredient talk to your doctor or someone on their team. They can usually prescribe a different medication that you are permitted to use. It can also help to discuss the medication with your community leader or a religious scholar, as they will be able to advise on your faith's specific laws.

Do not stop taking your medication - talk to your doctor.

An information sheet for patients concerning animal products in medications.

of trust in patients. Theological positions on this matter can be complex, but many faiths follow the overriding principle of medical necessity and exercise leniency to preserve life (Gatrad 2001; Spitzer 2003; Gatrad 2005; Usmani 2006).

\section{Conclusions}

This article has emphasised the importance for psychiatrists of taking into consideration the patient's personal and religious beliefs when

BOX 2 Approaches to avoid medication containing gelatin or stearic acid

Consider:

- using liquid or elixir preparations

- removing the drug from gelatin-containing capsules

- using non-sustained-release and non-orodispersible forms of the medication

- exploring both generic and branded forms of the drug as the gelatin and stearic acid composition may vary 
prescribing psychotropic medication. Some patients choose not to take certain medications, for example those containing gelatin (predominantly found in capsules), as it would be in direct contradiction of their religious practices. Having a basic understanding of a patient's religious beliefs can improve the doctor-patient relationship and, consequently, adherence to medication.

The interpretation of dietary laws in relation to the consumption of medication containing substances such as gelatin can vary between faiths and depending on a number of factors, including necessity to take the medication, the consequences of not taking it, the availability of alternative preparations and the route of administration (i.e. oral or parenteral). Religious leaders and scholars can be a useful point of contact for patients who have further questions on the subject and discussion can be facilitated through local mental health chaplains.

All psychiatrists should be aware of dietary requirements and food laws relating to psychotropic medication. However, comprehensive policy planning on such an important issue should ideally involve prescribing and non-prescribing healthcare professionals, pharmaceutical industry representatives, religious clerics, community leaders, the Vegetarian Society, the General Medical Council, carers and patients.

\section{References}

Adler A (2007) Kashrus of medicines and related products. Hakohol (Annual Magazine of Union of Orthodox Hebrew Congregation): 70-119.

Borras L, Mohr S, Huguelet P, et al (2007) Religious beliefs in schizophrenia: their relevance for adherence to treatment. Schizophrenia Bulletin, 33: 1238-46.

Campion J, Bhugra D (1997) Experience of religious healing in psychiatric patients in South India. Social Psychiatry and Psychiatric Epidemiology, 32: 215-21.

Chatters L, Taylor R, Lincoln K, et al (2008) Religious coping among African Americans, Caribbean Blacks and Non-Hispanic Whites. Journal of Community Psychology, 36: 371-86.

Dein S (2004) Working with patients with religious beliefs. Advances in Psychiatric Treatment, 10: 287-94.

Dogra N, Karim K (2005) Diversity training for psychiatrists. Advances in Psychiatric Treatment, 11: 159 -67.

Dresner S, Siegel S (1980) Jewish Dietary Laws (Revised edn). United Synagogue Book Service.

Eriksson A, Burcharth J, Rosenberg J (2013) Animal derived products may conflict with religious patients' beliefs. BMC Medical Ethics, 14: 48.

Food Standards Agency (2005) Consumer Attitudes to Food Standards 2004 (Wave 5). Food Standards Agency (http://www.food.gov.uk/ multimedia/pdfs/casuk04.pdf)

Gatrad AR, Sheikh A (2001) Medical ethics and Islam: principles and practice. Archives of Disease in Childhood, 84: 72-5.

Gatrad AR, Mynors G, Hunt P, et al (2005) Patient choice in medication taking: religious sensitivities must be respected. Archives of Disease in Childhood, 90: 983-4.

\section{Graham G (2004) Eight Theories of Ethics. Routledge.}

Hashim P, Ismail A, Sazili Q, et al (eds) (2009) Proceedings of the 3rd IMT-GT International Symposium on Halal Science and Management. 2009. Halal Products Research Institute, Universiti Putra Malaysia (http://www.academia.edu/457706/The_Theory_of_Istihalah_from_ Fiqh_Perspective_Analysis_of_Determining_halal_and_haram_for_ several_Food_Products).

Heber D (1995) Kosher medication year round and Pesach: does over the counter need to be under Hashgacha? Kashrus Kurrents, XV(3) (http://www.kashrut.com/articles/med).

Huguelet P, Mohr S, Brandt P-Y, et al (2006) Spirituality and religious practices among outpatients with schizophrenia and their clinicians. Psychiatric Services, 57: 366-72.

Kemmerer L (2011) Animals and World Religions. Oxford University Press.

Khokhar WA, Hameed I, Ali MM, et al (2008) To trust or not to trust? Faith issues in psychopharmacological prescribing. Psychiatric Bulletin, 32: $179-82$.

Koenig H, McCullough M, Larson, D (2001) Handbook of Religion and Health. Oxford University Press.

Leung D, Davies S, Wong S, et al (2005) Zyprexa Velotab (olanzapine): suitable for vegetarians? Psychiatric Bulletin, 29: 275-6.

McAllister-Williams H, Ramplin S (2009) Vegetarian psychotropics: a survey of psychotropic medications suitable for vegetarians. Human Psychopharmacology: Clinical and Experimental, 24: 248-50.

Meyer M (1988) Ethical principles of psychologists and religious diversity. Professional Psychology: Research and Practice, 19: 486-8.

Mohr S, Huguelet P (2004) The relationship between schizophrenia and religion and its implication for care. Swiss Medical Weekly, 134: 369-76.

Patel MX, David AS (2005) Why aren't depot antipsychotics prescribed more often and what can be done about it? Advances in Psychiatric Treatment, 11: 203-11.

Phelps N (2004) The Great Compassion: Buddhism and Animal Rights. Lantern Books.

Royal College of Psychiatrists (2004) College statement on covert administration of medicines. Psychiatric Bulletin, 28: 385-6.

Sattar P, Ahmed S, Majeed F, et al (2004a) Inert medication ingredients causing nonadherence due to religious beliefs. Annals of Pharmacotherapy, 38: 621-4

Sattar P, Ahmed S, Madison J, et al (2004b) Patient and physician attitudes to using medications with religiously forbidden ingredients. Annals of Pharmacotherapy, 38: 1830-5.

Secker J, Harding C (2002) User's perception of an African and Caribbean mental health resource centre. Health and Social Care in the Community, 10: 270-6.

Singsit S, Naik PC (2001) Remember the depressed vegetarian. British Journal of Psychiatry, 178: 184

Spitzer J (2003) Caring for Jewish Patients. Radcliffe Medical Press.

Subach A, Abdul-Ezz R (1999) Religious reasons for discrimination of immunosuppressive medication after renal transplant. Renal Failure, 21: $223-6$

Usmani M (2006) The Islamic Laws of Animal Slaughter. White Thread Press.

Walters KS, Portmess L (2001) Religious Vegetarianism: From Hesiod to the Dalai Lama. State University of New York Press.

Weiden P, Olfson M (1995) Cost of relapse in schizophrenia. Schizophrenia Bulletin, 21: 419-29.

Williams C (1997) Personal reflections on permanency planning and cultural competency. Journal of Multicultural Social Work, 5: 9-18.

\section{MCO answers \\ $1 \mathrm{c} \quad 2 \mathrm{~d} \quad 3 \mathrm{~b} \quad 4 \mathrm{~d} \quad 5 \mathrm{~d}$}




\section{MCOs}

Select the single best option for each question stem

1 A shared understanding of illness between clinicians and patients:

a increases relapse rates:

b increases mental distress

c improves treatment adherence

d has a negative impact on healthcare outcomes

e has a negative impact on the trust between them.

\section{There are clearly described rules for} slaughtering animals in:

a Christianity

b Hinduism

c Buddhism

d Judaism

e Jainism.
3 The most common source of animalderived gelatin used in medication:

a cows and goats

b cows and pigs

c cows and camels

d cows and fish

e pigs and poultry.

\section{Dietary vegans can consume:}

a meat

b eggs

c dairy products

d fruits

e gelatin.
5 All of the following approaches can be used to avoid taking medication that contains religiously forbidden ingredients except:

a using an elixir preparation of the same medication

b using a non-sustained-release form of the same medication

c using a generic form of the same medication

d involving a community leader or religious scholar

e using a non-orodispersible form of the drug. 